\title{
Task-specific reach-to-grasp training after stroke: development and description of a home-based intervention
}

\begin{tabular}{|c|c|}
\hline Journal: & Clinical Rehabilitation \\
\hline Manuscript ID: & CRE-2014-3797.R2 \\
\hline Manuscript Type: & Rehabilitation In Practice \\
\hline Keywords: & $\begin{array}{l}\text { Stroke, Upper extremity (arm), rehabilitation interventions, Physiotherapy, } \\
\text { Occupational therapy }\end{array}$ \\
\hline Abstract: & $\begin{array}{l}\text { Objective: } \\
\text { To describe and justify the development of a home-based, task-specific } \\
\text { upper limb training intervention to improve reach-to-grasp after stroke and } \\
\text { pilot it for feasibility and acceptability prior to a randomised controlled trial. } \\
\text { Intervention description: } \\
\text { The intervention is based on intensive practice of whole reach-to-grasp } \\
\text { tasks and part-practice of essential reach-to-grasp components. A 'pilot' } \\
\text { manual of activities covering the domains of self-care, leisure and } \\
\text { productivity was developed for the feasibility study. The intervention } \\
\text { comprises } 14 \text { hours of therapist-delivered sessions over } 6 \text { weeks, with } \\
\text { additional self-practice recommended for } 42 \text { hours (i.e. } 1 \text { hour every } \\
\text { day). As part of a feasibility randomised controlled trial, } 24 \text { people with a } \\
\text { wide range of upper limb impairment after stroke experienced the } \\
\text { intervention to test adherence and acceptability. The median number of } \\
\text { repetitions in } 1 \text {-hour therapist-delivered sessions was } 157 \text { (IQR: } 96-211 \text { ). } \\
\text { The amount of self-practice was poorly documented. Where recorded, } \\
\text { median amount of practice was } 30 \text { minutes (IQR: } 22-45 \text { ) per day. Findings } \\
\text { demonstrated that the majority of participants found the intensity, content } \\
\text { and level of difficulty of the intervention acceptable, and the programme to } \\
\text { be beneficial. Comments on the content and presentation of the self- } \\
\text { practice material were incorporated in a revised 'final' intervention } \\
\text { manual. } \\
\text { Discussion: }\end{array}$ \\
\hline
\end{tabular}

\section{SCHOLARONE \\ Manuscripts}




\title{
Task-specific reach-to-grasp training after stroke:
}

\section{development and description of a home-based intervention}

\section{[Clinical Rehabilitation - 'Rehabilitation in Practice']}

\author{
Authors: Paul Cunningham ${ }^{1}$, Ailie Turton ${ }^{1}$, Frederike Van Wijck ${ }^{2}$ and Paulette Van Vliet ${ }^{3}$. \\ ${ }^{1}$ Department of Allied Health Professions, University of the West of England, Bristol, UK. \\ ${ }^{2}$ Institute for Applied Health Research, Glasgow Caledonian University, UK. \\ ${ }^{3}$ Faculty of Health, University of Newcastle, Australia.
}

Author Contributions:

\begin{tabular}{|l|l|}
\hline Person & Relevant activities contributed \\
\hline Paul Cunningham & $\begin{array}{l}\text { Development of the intervention and manual, testing feasibility, writing } \\
\text { - lead authorship. }\end{array}$ \\
\hline Dr. Ailie Turton & Development of the intervention and manual, testing feasibility, writing \\
\hline Prof. Frederike vanWijck & Development of the intervention and manual, writing - contributing \\
& significant text. \\
\hline Prof. Paulette VanVliet & Development of the intervention and manual, writing - contributing \\
& significant text. \\
\hline
\end{tabular}




\section{Acknowledgements:}

The authors would like to thank Research Associates (Emma Heron and Verity Longley), Stroke Research Network officers (Sarah Hierons, Sarah Dunn and Amy Steele); Principal Investigators (Colin Domaille, Becky Woodward, Chris Easton, Rhiannon Ferguson-Thomas and Fiona Henchie) and local collaborators (Bryony Williams and Martin Boyd) for their assistance throughout the duration of the feasibility study. We would also like to thank Professor Steven Wolf for reviewing and providing comments on the manuscript.

\section{Supplementary Materials:}

There are two online data supplements available alongside this article:

1: 'Sample Section of Intervention Manual' - containing the cover and contents list of the final intervention manual and providing examples of activity sheets designed to support delivery of the intervention

2. 'Intervention Questionnaire' - detailing the questionnaire used to obtain participants' perspectives of the intervention and the qualitative responses in full.

For details of the research methods used in the 'feasibility randomised controlled trial of homebased reach-to-grasp training for people after stroke' associated with this article, the study protocol is published in the journal Trials and is available at: www.trialsjournal.com/content/14/1/109

\section{Contact Details:}

The authors can be contacted for any further details at: paul6.cunningham@uwe.ac.uk 
Task-specific reach-to-grasp training after stroke:

\author{
development and description of a home-based intervention
}

\title{
[Clinical Rehabilitation - 'Rehabilitation in Practice']
}

\begin{abstract}
: 236 words
Objective:

To describe and justify the development of a home-based, task-specific upper limb training intervention to improve reach-to-grasp after stroke and pilot it for feasibility and acceptability prior to a randomised controlled trial.

Intervention description:

The intervention is based on intensive practice of whole reach-to-grasp tasks and partpractice of essential reach-to-grasp components. A 'pilot' manual of activities covering the domains of self-care, leisure and productivity was developed for the feasibility study. The intervention comprises 14 hours of therapist-delivered sessions over 6 weeks, with additional self-practice recommended for 42 hours (i.e. 1 hour every day). As part of a feasibility randomised controlled trial, 24 people with a wide range of upper limb impairment after stroke experienced the intervention to test adherence and acceptability.
\end{abstract}


The median number of repetitions in 1-hour therapist-delivered sessions was 157 (IQR: 96211). The amount of self-practice was poorly documented. Where recorded, median amount of practice was 30 minutes (IQR: 22-45) per day. Findings demonstrated that the majority of participants found the intensity, content and level of difficulty of the intervention acceptable, and the programme to be beneficial. Comments on the content and presentation of the self-practice material were incorporated in a revised 'final' intervention manual.

\section{Discussion:}

A comprehensive training intervention to improve reach-to-grasp for people living at home after stroke has been described in accordance with the TIDieR reporting guidelines. The intervention has been piloted, found to be acceptable and feasible in the home setting.

\section{Keywords:}

Stroke, Hand, Arm, Upper Limb, Physical therapy, Occupational therapy, Rehabilitation, Home, Reach, Grasp, Repetitive, Task-specific training, Practice

Trial registration: ISRCTN56716589 


\section{Introduction:}

Task-specific training is recommended internationally in stroke rehabilitation guidelines ${ }^{1-4}$ and involves intensive practice of actions or functional tasks. ${ }^{5}$ A Cochrane overview of systematic reviews concluded that there was moderate quality evidence that at least 20 additional hours of repetitive task training was effective for improving upper limb function after stroke but that sufficiently powered, high-quality randomised controlled trials were required to strengthen the evidence. ${ }^{6}$ Task-specific upper limb training specifically focusing on reach-to-grasp movements would appear to be particularly relevant, as stroke survivors consulted about their goals for upper limb therapy programmes prioritised activities involving reach-to-grasp., ${ }^{7,8}$ Reach-to-grasp movements are essential for everyday functions such as retrieving objects, e.g. clothes, food and drink, and are used more frequently than other upper limb movements such as gesturing, stabilising objects or for postural support. ${ }^{9}$

With the implementation of early-supported discharge services, upper limb rehabilitation after stroke is increasingly being provided at home. Home-based training is likely to be influenced by environmental and psychosocial factors and currently there is insufficient evidence for the effectiveness of home-based therapy for improving functional recovery of the upper limb after stroke. ${ }^{10}$ Therefore, interventions involving high-intensity task-specific training focusing on reach-to-grasp activities need to be developed for the home setting.

Developing feasible, evidence-based, meaningful therapeutic interventions is a key aim of neurological rehabilitation research. ${ }^{11}$ However, only $39 \%$ of non-pharmacological 
interventions evaluated in randomised trials are adequately described, ${ }^{12}$ meaning clinicians do not have sufficient information to deliver tested interventions to patients. ${ }^{13}$

The intervention was developed in the context of the UK Medical Research Council (MRC) framework for developing and evaluating complex interventions, which describes the need to identify evidence, model the intervention for delivery and test feasibility, prior to testing effectiveness in a definitive evaluation. ${ }^{14,15}$ The aim of this article is to explain the development process, describe and justify the essential components of this intervention and report its feasibility and acceptability amongst stroke survivors and therapists. The work was carried out as part of a feasibility randomised controlled trial of a home-based taskspecific reach-to-grasp training intervention for people after stroke (Trial registration: ISRCTN56716589).

\section{Intervention Description:}

The 'Template for Intervention Description and Replication' (TIDieR) checklist ${ }^{16}$ has been used to structure the description of this intervention. The 12 checklist items are displayed in Table 1 alongside how each has been interpreted for this intervention description.

\section{[insert Table 1 here]}


The development process involved producing a 'pilot' manual that was used to standardise the delivery of the intervention in the feasibility study. The pilot manual is published alongside the feasibility study protocol ${ }^{17}$ and available to view at: http://www.trialsjournal.com/content/supplementary/1745-6215-14-109-s2.pdf.

During the feasibility study, feedback and other data were collected from participants and therapists, as per the study protocol, ${ }^{17}$ and results relevant to the intervention development and description are presented in this paper. This information was incorporated into the development of a revised 'final' intervention manual. To assist understanding of the intervention, the contents list and a selection of activity sheets taken from the final manual are provided in the 'Sample Section of Intervention Manual' online data supplement.

The entire final manual is not currently publicly available in order to minimise influence on usual care until a planned Phase III randomised controlled trial is completed. The final manual will then be made available in full, irrespective of outcome, on the 'Research Repository' of the University of the West of England at http://eprints.uwe.ac.uk.

\section{Name: Intervention title}

Home-based task-specific reach-to-grasp training after stroke.

\section{Why: Rationale, definition and essential elements of the intervention}

To improve a functional skill, training needs to focus on practising that specific skill - a principle known as task-specific training., A variety of terms for task specific training have been used in the literature. ${ }^{5,7,18,19}$ The Cochrane review of repetitive task training defined 
studies eligible for inclusion as those "where an active motor sequence was performed repetitively within a single training session, and where the practice was aimed towards a clear functional goal" ${ }^{5}$ However, considering that many people with stroke cannot complete a task in its entirety, we expanded this definition to include 'part-practice'. 'Partpractice', as described by Carr and Shepherd, ${ }^{20}$ involves undertaking tasks through segmentation; for example, the reach-to-grasp action is broken down into parts (e.g. shoulder flexion) that can be practised separately. Progression can take place by 'chaining', i.e. practising first one part, then practising that part with the next and so on, aiming for mastery of the whole task. ${ }^{21}$ Consequently, for our intervention, 'task-specific reach-tograsp training' was defined as: 'A progressive training programme comprising practice of whole reach-to-grasp tasks and, where required, practice of the component parts that can be systematically reassembled into the whole task, with the aim of improving reach-to-grasp ability in daily activities'.

The intervention was based on biomechanical analysis of functional reach-to-grasp movements and principles of motor learning. ${ }^{22,23}$ To be 'task-specific', each action must specify an object to reach for, move towards, or to grasp when either the whole task, or a component, is practised. Another requirement was that the practice should be carried out under conditions as similar to the conditions of the target task as possible to enhance carryover into everyday living. Parameters considered were the: amplitude and direction of movement, available joint range, degrees of freedom, size/dimensions of the object(s), load, speed and the amount of gravity/friction to be overcome. 
Examples and descriptions of reach-to-grasp activities, for people with impaired shoulder and elbow movement, are provided in Table 2. The activity sheets for these examples are provided in the 'Sample Section of Intervention Manual' online data supplement.

\section{[insert Table 2 here]}

\section{What - materials: Intervention manual}

To enable standardised delivery of the intervention in the feasibility trial, the pilot manual of activities was designed based on the invariant kinematic features of reach-to-grasp actions, i.e.: shoulder flexion; scapular protraction and lateral rotation; shoulder external rotation; elbow extension; forearm supination; wrist extension and radial deviation; thumb abduction and opposition; finger extension with interphalangeal joints in some flexion. ${ }^{22}$ Guidance notes for therapists based on the general principles of task-specific reach-to-grasp training prefaced the activities. These described procedures for the assessment of reach-to-grasp using a checklist of the invariant kinematic features of reach-to-grasp actions and how activities could be varied to suit the goals of each participant and optimise progression.

The pilot manual contained part-practice activities for each of the invariant kinematic features and a 'whole reach-to-grasp tasks' section, which incorporated sequential and simultaneous combinations of the invariant kinematic features into whole tasks. Activities for each part-practice section were based on the authors' clinical and research experience along with suggestions from clinical colleagues and relevant exercises from an open-access physiotherapy website. ${ }^{24}$ Part practice activities were ordered by difficulty (e.g. by the 
number of joints involved and the amount of gravity or resistance encountered). 'Whole task' activities covered the domains of self-care (e.g. brushing hair, putting on socks/shoes and tying laces, zipping/buttoning clothes), productivity (washing cutlery/crockery, using a knife and fork, pegging out and folding washing) and leisure (e.g. operating mobile phones and remote controls, knitting, playing cards or other games requiring dexterity), identified as common goals by people after stroke. ${ }^{7,8}$

All activities were discussed by the authors and included/excluded based on the previously agreed definition of task-specific reach-to-grasp training. Instructions were drafted for each activity and reviewed by the authors for clarity for participants. Photographs of the authors performing each activity were included. The pilot manual was reviewed by two people living with stroke, one with aphasia, who provided their views on the overall design and the feasibility of individual activities, following which the pilot manual was amended accordingly. The pilot manual, used in the feasibility study, contained 122 activities.

\section{What - procedures: Role of therapist}

At the initial intervention visit, the therapist delivering the intervention assessed each participant against a checklist of the invariant kinematic features to guide a biomechanical analysis of functional reach-to-grasp movements. Following this assessment, the therapist selected activities from the pilot manual and provided the participant with a folder containing colour copies of their activity sheets. At each subsequent visit, the therapist reassessed the reach-to-grasp movement and progressed/amended activities as appropriate for the individual. During each supervised session the therapist aimed to maximise the number of repetitions of activities performed and encouraged participants to self-practise a maximum number of repetitions daily between visits. 


\section{Who provided: Therapist delivering intervention}

The reach-to-grasp training was delivered primarily by one research physiotherapist with absence cover provided by two additional therapists (one a Physiotherapist and one an Occupational Therapist) as required. All three therapists had worked as senior community therapists in the UK National Health Service and were trained and experienced in using upper limb task-specific training with people after stroke.

\section{How: Method of delivery}

The intervention was delivered on a one-to-one basis to promote engagement and motivation with the intervention and, importantly, allow specific feedback on performance; a key principle of skill acquisition. Extrinsic feedback (e.g. feedback provided by a therapist) can be focused either on the body movement (internal focus) or on the effects of the movement on the environment (external focus). ${ }^{21}$ For this intervention, feedback on movement quality (i.e. an internal focus) was used only to avoid movement patterns that might potentially be detrimental to acquiring the required action; in all other instances, feedback was provided on the target / goal of the activity (i.e. an external focus). The choice of feedback focus was based on previous work on the role of feedback on improving reachto-grasp function in people after stroke ${ }^{25}$ and the findings of a recent systematic review that extrinsic feedback with an external focus, augments motor learning in stroke survivors. ${ }^{26}$

Family and carer engagement is strongly associated with good rehabilitation outcomes. ${ }^{27,28}$ It is difficult however to standardise the potential influence and involvement of carers. Instructions for therapists delivering the reach-to-grasp intervention were therefore limited to advising carers to remind and encourage participants to practise, asking them to set up equipment and assist in recording the amount of practice. 


\section{Where - Environment and equipment}

The intervention was delivered in participants' own homes, including care homes, as homebased rehabilitation has the potential to facilitate context dependent learning; objects of relevance to the participant can be easily incorporated (e.g. comb, cutlery, cupboards) to allow occupational embedding of the activities. ${ }^{29}$ As such, a variety of objects, preferably used by participants in everyday life, were selected for activity practice as varying object shape and size can influence movement kinematics. ${ }^{30}$

\section{When and how much - Timing and Intensity of training}

The intervention was designed to be delivered once participants had returned home from hospital and within the first 12 months after stroke. Participants $(n=24)$ who received the intervention in the feasibility study were a median of 111.5 days (IQR: 82.0, 241.0), approximately 4 months, after stroke.

The intensity of the intervention encompasses the total amount of treatment, as well as its distribution over the treatment period in terms of the number, frequency and duration of individual treatment sessions, and the number of repetitions within each session.

Uncertainty remains regarding optimal total therapy dosage for motor recovery after stroke but there is evidence to support higher doses, ${ }^{10,31}$ for example, the EXCITE trial of constraint-induced movement therapy demonstrated significant improvement in upper limb function after stroke with an intended dose of 60 hours of practice. ${ }^{32}$ Consequently, with consideration given to the feasibility of delivery in community rehabilitation services, the treatment schedule for this reach-to-grasp intervention was set at a total target dose of 56 hours. This consisted of 14 , one hour, therapist visits over six weeks and additional self- 
monitored practice recommended for an hour a day, seven days a week. The frequency of therapist visits was tapered, three times a week in the first three weeks, twice in each of the next two weeks, then once in the final week, with the aim of increasing self-efficacy in practice and fostering self-management.

In terms of the number of repetitions within each session, high-intensity training was implemented. This is a key principle of the intervention based on animal studies of neuroplasticity ${ }^{33-35}$ and meta-analyses of stroke rehabilitation trials. ${ }^{10}$ However, no clear guidelines on the optimum number of repetitions currently exist. ${ }^{28}$ A study of moderately affected stroke participants demonstrated that 300 repetitions were achievable within a one hour training session. ${ }^{36}$ With this in mind and to include those with severe impairment, a target range of 100-300 repetitions/hour was endeavoured, dependent on individual participant's capabilities.

\section{Tailoring - Individualising the intervention}

The most important predictor of outcome for upper limb recovery is severity of motor impairment and function. ${ }^{37}$ Participants receiving the intervention in this study had substantial loss of upper limb function: median ARAT score $=8.5$ (IQR 3.0; 24.0) (ARAT score range: $\min .0$ - $\max .57)$.

Due to the range of upper limb impairment, the therapist needed to select activities to suit the functional ability of each participant with consideration also given to factors such as the patient's home environment, individual preferences, level of carer support, object shape and size, target positions and speed of movement. 
As this was a structured intervention, the scope for individualised goal setting was limited to each participant being encouraged to identify the tasks, objects and environments for practice, with the intention to make the intervention more personally relevant and stimulate engagement. ${ }^{38}$

\section{How well - planned: How was adherence recorded}

For the 14 treatment sessions, the number of repetitions and time spent on each activity from the pilot manual was recorded by the therapist using a tally counter and stop watch. For independent practice, participants were asked to record repetitions and time for each activity using log sheets covering the six week duration of the intervention.

At the final intervention visit, a face-to-face, semi-structured interview was completed using a questionnaire designed to gauge the views of participants on the intensity and content of the intervention, as well as the design of the activity sheets. The questionnaire used is presented in the 'Intervention Questionnaire' online data supplement. The questions were asked by the research physiotherapist responsible for delivery of the intervention. While this may have biased responses, it was anticipated to facilitate a better understanding of any changes that should be made to the content of the intervention.

\section{How well - actual: Results for intervention adherence and acceptability}

A high intensity of therapist-supervised training was achieved with $94 \%$ of planned visits completed (median 14; IQR 13.0, 14.0) and a median of 157 (IQR 96, 211) repetitions completed within each one hour visit. Participants were engaged in upper limb practice for a median of 38.5 minutes (IQR 35.4, 48.8) per therapist-supervised session as time was required for assessment and to set-up and move between activities. During each one hour 
therapist visit, the average number of activities practised was 4 (SD: 1.3; range: 1 to 7). Over the six week intervention period, participants practised an average of 16.1 (SD: 3.8; range: 7 to 23 ) different activities. The majority of participants (17 of the 24 ) reported that practising independently for an hour per day was acceptable. Logs of participants' practice were poorly completed, but from those which were recorded, the median was only 30.0 minutes of independent practice per day (IQR: 22.2, 44.5).

All 24 participants completed the treatment questionnaire. Analysis of responses shows that all participants who provided an answer $(n=23)$ considered the intervention to be acceptable. A total of 16 participants considered the number of visits to be acceptable; the remaining eight would have preferred more. The intervention appeared to be provided at an appropriate level of difficulty with participants reporting a median of 6 out of 10 (IQR:

$5.0,7.5)$ for how difficult the treatment was on a visual analogue scale where 0 represented extremely difficult and 10 represented extremely easy (Table 3).

\section{[insert Table 3 here]}

Qualitative responses regarding the benefits of the treatment highlight participants' perceived improvements, particularly in confidence, e.g. "more confidence to try things in my life" and "made me feel more confident that things are going to move on in the future". These translated into a wide variety of reported functional gains such as being able to "put on and take off wheelchair brake", "put on own socks and tie shoe laces", "steady a bowl/plate to eat with right hand", "brush hair" and "able to reach for Zimmer frame by 
myself, meaning I can walk by myself". The full list of qualitative responses are presented in the accompanying 'Intervention Questionnaire' online data supplement.

The questionnaires also asked participants' opinions about the design of the activity sheets. The visual aspect of the activity sheets was evaluated positively by 16 of the 24 participants. However two participants thought that the photographs would be improved by featuring people who have had a stroke rather than healthy individuals, commenting that "it's better to have people who have had a stroke - see there are other people like you" and that the current activity sheets show people who "obviously don't have problems, which is a bit of a slap in the face". Three participants who had commented that the original photographs on the activity sheets were "too straight-laced, not realistic", "could be more contemporary" and "should be 'busier' like people's houses". Participants also commented that there should be more space for additional writing. Additionally, participants were asked which of the activities that they had practised they either 'liked' or 'disliked'.

\section{Modifications: Revising the intervention following feasibility study}

Following completion of the feasibility study, the pilot manual was revised, based on participant feedback and, following ethics committee approval and participant consent, to include photographs of participants with stroke practising the activities in their home environments. The authors then reviewed the ten activities which received more 'dislikes' than 'likes' from participants; it was decided that these activities had potential therapeutic merit and should continue to be included in the final manual but the instructions and photographs be revised to improve understanding and acceptability. 
The frequencies of activities prescribed to participants were calculated: 44 of the original 122 activities had not been assigned for independent practice. These 44 activities were individually reviewed by the authors and consensus decisions were made to remove ten of them. Next, a group consultation with the three therapists involved in the delivery of the intervention, one of whom was external to the research team and therefore able to provide a more independent assessment, was undertaken about their use of the pilot manual. The therapists were in favour of the number and variety of activities in the pilot manual but reported difficulties finding and selecting activities from such an extensive resource. As a result, the final manual was re-structured to optimise ease of use with the classification of grip types described by Napier $(1956)^{39}$ incorporated into the indexing to structure the 'grasp' sections, while all sections were colour-coded to aid navigation. Additional activities suggested by the research therapists were included in the final manual, where authors were in agreement, with a final total of 144 activities. Changes to the format of the self-practice activity sheets were also made; the examples provided in the 'Sample Section of Intervention Manual' online data supplement are taken from the final manual.

\section{Discussion:}

This article has described, as per the TIDieR reporting guidelines, ${ }^{16}$ an intensive task-specific reach-to-grasp training intervention for people after stroke for use in their own homes, as well as its development and piloting. Justification for the intervention is provided based on current best evidence and principles of skill acquisition. This process has resulted in a comprehensive intervention and final manual to support and structure its delivery. The 
intervention was considered acceptable by participants and therapists, and can be used in a subsequent pragmatic randomised controlled trial.

Standard study reports do not usually permit sufficient detail of intervention description, particularly for reports of complex non-pharmacological interventions. ${ }^{12,13}$ The 'TIDieR' guidelines used here have provided a structured framework which has ensured that all factors relevant to the delivery of the complex intervention have been described in detail. A limitation of the 'TIDieR' guidelines for this report is that they are primarily for describing an intervention but not the process of how the intervention was developed. For this report therefore, a number of items required interpretation to also describe the rationale for decisions made during the development of the intervention.

Owing to the high-intensity of practice involved in the intervention, an important finding of the feasibility study was the acceptability of the intervention as evidenced by the completion of the majority of therapist visits and the completion of a median number of repetitions per visit within the pre-specified target range of 100-300 per hour. Within each visit participants were engaged in upper limb practice for approximately two-thirds of the available therapy time which interestingly replicates findings from a retrospective analysis of the EXCITE trial in which participants were engaged in upper limb training for $62 \%$ of the in-laboratory time. ${ }^{40}$

The majority of participants in this feasibility study considered an hour/day of independent practice to be acceptable. However, the self-report practice logs showed that participants actually practised, on average, for only half this time. This finding should be interpreted carefully as compliance with the logs was limited. Difficulties in accurately recording independent practice have been reported previously, ${ }^{41}$ however methods for improving, as 
well as capturing, adherence in independent practice still need to be identified to improve the accuracy of trials and quality of clinical rehabilitation. To enhance intervention adherence, a number of practical strategies were identified and/or developed during the feasibility study:

- To encourage participants to focus on increasing repetitions rather than number of activities it was established that a maximum of four activities would be provided for selfpractise at any one time, i.e. additional activities needed to replace previous activities.

- To promote self-monitoring of repetitions during independent practice, participants were offered a hand-held tally counter. For some participants, this appeared to improve both adherence and accuracy of recording although this requires further investigation.

- To achieve high numbers of repetitions, it was necessary for treatment sessions to be highly structured, which was perceived as different to usual care therapy sessions and some participants found challenging. Sessions appeared to be better tolerated however if they were described as "training" rather than "therapy" and an explanation provided on the intended effects of high-intensity training on neuroplasticity and motor learning.

Consultation with participants and therapists has led to an improved intervention manual intended to be used to structure and standardise the delivery of the training intervention in a randomised controlled trial. Although this manual is currently designed to be used in print format, an electronic version could be used in the future, for example in the context of telemedicine, where therapists could provide feedback and suggest new activities, and patients could report their experiences, and, photographs/videos of recommended exercises or patient performance could be uploaded. The current study is an initial step in the evolution of the content and delivery of the intervention. 


\section{Clinical messages:}

- A home-based task-specific reach-to-grasp training programme for people after stroke has been described and a manual has been developed to enable systematic and standardised delivery.

- The high-intensity task-specific intervention was considered acceptable and beneficial by participants and feasible for use in the home setting.

\section{Competing Interests:}

The authors declare no conflict of interest.

\section{Funding Support:}

This study was supported by the Stroke Association (TSA 2009/01). Additional funding was provided by the Stroke Research Network for the design of the final intervention manual. The views expressed in this paper are those of the authors and may not necessarily be shared by the funding body. 


\section{References:}

1. Intercollegiate Stroke Working Party. National clinical guideline for stroke. 4th ed. Royal College of Physicians, London, 2012.

2. National Institute for Health and Care Excellence. Stroke rehabilitation [CG162]. National Institute for Health and Care Excellence, London, 2013

3. National Stroke Foundation. Clinical guidelines for stroke management. National Stroke Foundation, Melbourne, Australia, 2010

4. Dawson AS, Knox J, McClure A, et al. Chapter 5: Stroke rehabilitation. In: Lindsay MP, Gubitz G, Bayley M, Phillips S: Canadian best practice recommendations for stroke care. $4^{\text {th }}$ ed. Ottawa, Ontario, Canada, July 2013.

5. French B, Thomas LH, Leathley MJ, et al. Repetitive task training for improving functional ability after stroke. Cochrane Database Syst Rev 2007; Issue 4.

6. Pollock A, Farmer SE, Brady MC, et al. Interventions for improving upper limb function after stroke. Cochrane Database Syst Rev 2014; Issue 11.

7. Timmermans AA, Seelen HA, Willmann RD, et al. Arm and hand skills: training preferences after stroke. Disabil Rehabil 2009; 31(16): 1344-1352.

8. van Wijck F, Shaw L, Price C, et al. Botulinum Toxin for the Upper Limb after Stroke (BoTULS) trial: effect on patient-selected goals versus a standard arm function test. In: World Stroke Congress, Oct. 10-13 2012, Brasilia, Brazil.

9. Kilbreath SL and Heard RC. Frequency of hand use in healthy older persons. Aust J Physiother 2005; 51(2): 119-122.

10. Coupar F, Pollock A, Legg LA, et al. Home-based therapy programmes for upper limb functional recovery following stroke. Cochrane Database Syst Rev 2012, Issue 5. 
11. Dobkin, B. Progressive staging of pilot studies to improve phase III trials for motor interventions. Neurorehabil Neural Repair 2009; 23: 197-206.

12. Hoffmann TC, Erueti C and Glasziou PP. Poor description of non-pharmacological interventions: analysis of consecutive sample of randomised trials. BMJ 2013; 347: f3755

13. Cook A, Douet L and Boutron I. Descriptions of non-pharmacological interventions in clinical trials. BMJ 2013; 347: f5212.

14. Medical Research Council. A framework for the development and evaluation of RCTs for complex interventions to improve health. Medical Research Council, London, 2000.

15. Craig P, Dieppe $P$, Macintyre $S$, et al. Developing and evaluating complex interventions: the new Medical Research Council guidance. BMJ 2008; 337: 979-983.

16. Hoffmann TC, Glasziou PP, Boutron I, et al. Better reporting of interventions: template for intervention description and replication (TIDieR) checklist and guide. BMJ 2014; 348: g1687.

17. Turton AJ, Cunningham P, Heron E, et al. Home-based reach-to-grasp training for people after stroke: study protocol for a feasibility randomized controlled trial. Trials 2013; 14 : 109.

18. Cha YJ, Yoo EY, Jung MY, et al. Effects of functional task training with mental practice in stroke: a meta analysis. NeuroRehabilitation 2012; 30(3): 239-246.

19. Michaelsen SM, Dannenbaum R and Levin MF. Task-specific training with trunk restraint on arm recovery in stroke: randomized control trial. Stroke 2006; 37: 186-192.

20. Carr JH and Shepherd RB. A motor relearning programme for stroke. 2nd ed. Oxford, UK: William Heinemann Medical Books, 1987, p.45-46.

21. Magill RA. Motor learning: Concepts and applications. 9th ed. McGraw-Hill, 2010. 
22. Carr JH and Shepherd RB. Neurological rehabilitation: optimizing motor performance. 2nd ed. Elsevier Churchill Livingstone, 2010.

23. Schmidt RA and Lee TD. Motor control and learning - a behavioural emphasis. 5th ed. University of Michigan: Human Kinetics, 2011.

24. Messenger P. Physiotherapy Exercises, www.physiotherapyexercises.com (2014, accessed 30 June 2014).

25. Durham KF, Sackley CM, Wright CC, et al. Attentional focus of feedback for improving performance of reach-to-grasp after stroke. Physiotherapy (2014); 100: 108-115.

26. Subramanian SK, Massie CL, Malcolm MP, et al. Does provision of extrinsic feedback result in improved motor learning in the upper limb poststroke? A Systematic Review of the Evidence. Neurorehabil Neural Repair 2010; 24: 113-124.

27. Harris JE, Eng JJ, Miller WC, et al. The role of caregiver involvement in upper-limb treatment in individuals with subacute stroke. Phys Ther 2010; 90(9): 1302-1310.

28. Langhorne P, Bernhardt J and Kwakkel G. Stroke rehabilitation. Lancet 2011; 377: 16931702.

29. Trombly CA and Wu C. Effect of rehabilitation tasks on organization of movement after stroke. Am J Occup Ther 1999; 53: 333-347.

30. Van Vliet P, Kerwin DG, Sheridan MR, et al. The influence of functional goals on the kinematics of reaching following stroke. JNPT 1995; 19 (1): 11-16.

31. Cooke E, Mares K, Clark A, et al. The effects of increased dose of exercise-based therapies to enhance motor recovery after stroke: a systematic review and metaanalysis. BMC Medicine 2010; 8: 60.

32. Wolf SL, Winstein CJ, Miller JP, et al. Effect of constraint-induced movement therapy on upper extremity function 3 to 9 months after stroke. JAMA 2006; 296(17): 2095-2104. 
33. Hubbard IJ, Parsons MW, Neilson C, et al. Task-specific training: evidence for and translation to clinical practice. Occ Ther Int 2009; 16(3-4): 175-189.

34. Nudo RJ and Milliken GW. Reorganization of movement representations in primary motor cortex following focal ischemic infarcts in adult squirrel monkeys. $J$ Neurophysiol 1996; 75: 2144-2149.

35. Kleim JA, Barbay S and Nudo RJ. Functional reorganization of the rat motor cortex following motor skill learning. J Neurophysiol 1998; 80: 3321-3325.

36. Birkenmeier RL, Prager EM and Lang CE. Translating animal doses of task-specific training to people with chronic stroke in one hour therapy sessions: a proof-of-concept study. Neurorehabil Neural Repair 2010, 24(7): 620-635.

37. Coupar F, Pollock A, Rowe $P$, et al. Predictors of upper limb recovery after stroke: a systematic review and meta-analysis. Clin Rehabil 2012; 26(4): 291-313.

38. Sugavanam T, Mead G, Bulley C, et al. Goal setting after stroke: a systematic review of effects and experiences. Disabil Rehabil 2013; 35(3): 177-190.

39. Napier, JR. The prehensile movements of the human hand. J Bone Joint Surg Br 1956; 38(4): 902-913.

40. Kaplon RT, Prettyman MG, Kushi CL, et al. Six hours in the laboratory: a quantification of practice time during constraint-induced therapy (CIT). Clin Rehabil 2007; 21(10): 950958.

41. Stone AA, Shiffman S, Schwartz JE, et al. Participant non-compliance with paper diaries. BMJ 2002; 324: 1193. 
Table 1:

\begin{tabular}{|l|l|l|}
\hline \multicolumn{2}{|l|}{ TIDIER Checklist } & \\
\hline $\mathbf{1}$ & Name & Intervention title \\
\hline $\mathbf{2}$ & Why & Rationale, definition and essential elements of the intervention \\
\hline $\mathbf{3}$ & What - materials & Intervention manual \\
\hline $\mathbf{4}$ & What - procedures & Role of therapist \\
\hline $\mathbf{5}$ & Who provided & Therapist delivering intervention \\
\hline $\mathbf{6}$ & How & Method of delivery \\
\hline $\mathbf{7}$ & Where & Environment and equipment \\
\hline $\mathbf{8}$ & When and How much & Intensity of training \\
\hline $\mathbf{9}$ & Tailoring & Individualising the intervention \\
\hline $\mathbf{1 0}$ & How well - planned & How was adherence recorded \\
\hline $\mathbf{1 1}$ & How well - actual & Results for intervention adherence and acceptability \\
\hline $\mathbf{1 2}$ & Modifications & Revising the intervention following feasibility study \\
\hline
\end{tabular}


Table 2: Examples of reach-to-grasp activities for people with impaired shoulder and elbow movement.

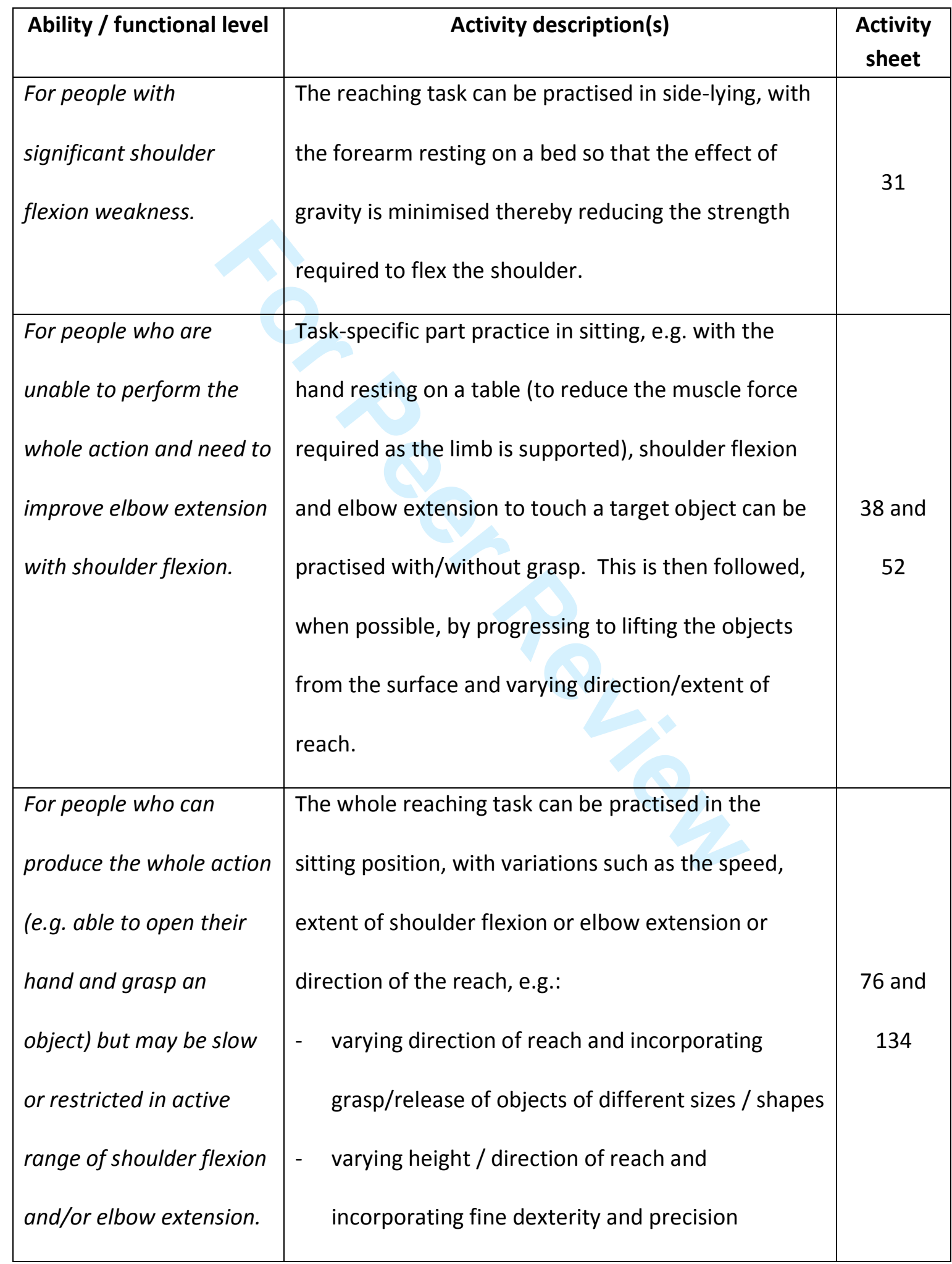


Table 3. Responses to questionnaire about experience of reach-to-grasp intervention $(n=24)$. The questionnaire used and all qualitative responses (Questions 5 and 7) are reported in the online 'Intervention Questionnaire' data supplement.

\begin{tabular}{|c|c|c|c|c|}
\hline & $\mathrm{n}$ & $\%$ & Median & IQR \\
\hline 1. Number of visits acceptable: & 16 & $66.7 \%$ & & \\
\hline 2. 1 hour/day independent practice acceptable: & 17 & $70.8 \%$ & & \\
\hline 3. Reach-to-grasp intervention acceptable: & 23 & $95.8 \%$ & & \\
\hline $\begin{array}{l}\text { 4. Reach-to-grasp intervention beneficial (0-10 VAS } \\
\text { scale; } 0=\text { not beneficial at all, } 10=\text { extremely } \\
\text { beneficial): }\end{array}$ & & & 8.0 & $(7.5,8.0)$ \\
\hline $\begin{array}{l}\text { 6. Reach-to-grasp intervention made difference to use } \\
\text { of arm: }\end{array}$ & 20 & $83.3 \%$ & & \\
\hline $\begin{array}{l}\text { 8. Reach-to-grasp intervention worth the amount of } \\
\text { effort required: }\end{array}$ & 23 & $95.8 \%$ & & \\
\hline $\begin{array}{l}\text { 9. Reach-to-grasp intervention difficult (0-10 VAS } \\
\text { scale; } 0=\text { extremely difficult, } 10=\text { extremely easy): }\end{array}$ & & & 6.0 & $(5.0,7.5)$ \\
\hline
\end{tabular}




\section{Home-based} task-specific training for arm and hand recovery after stroke 


\section{Sections}

\section{Shoulder}

- Protracton

- Flexion

- Extension

- Abducton

- External rotation - forearm supported

\section{Shoulder + elbow}

- External rotation forearm unsupported

- Shoulder extension with elbow extension

- Shoulder flexion with elbow extension

\section{Forearm}

- Pronation/supination - forearm supported

- Pronation/supination - forearm unsupported

\section{Wrist}

- Extension

- Radial deviation

- Extension and radial deviation
- Finger extension

- Thumb abduction

- Finger extension and thumb abduction maintaining static forearm position

- Finger extension, thumb abduction and elbow movement

\section{Power grasp}

- Power grasp maintaining static forearm

- Power grasp and elbow movement

\section{Precision grasp}

- Pinch grip between index finger and thumb

- Pinch grip with transport maintaining static forearm position

- Pinch grip with transport and elbow movement

- Conjunct rotation

- Bimanual tasks involving precision grasps

\section{Combined grasp}

- Tasks requiring power and precision grasps 


\section{Reach along bed to touch}

- $\quad$ Lying on your side with your weaker arm upper most

- $\quad$ Reach along the bed to try to touch a target

- Try to keep your elbow straight, shoulders level and not to roll over
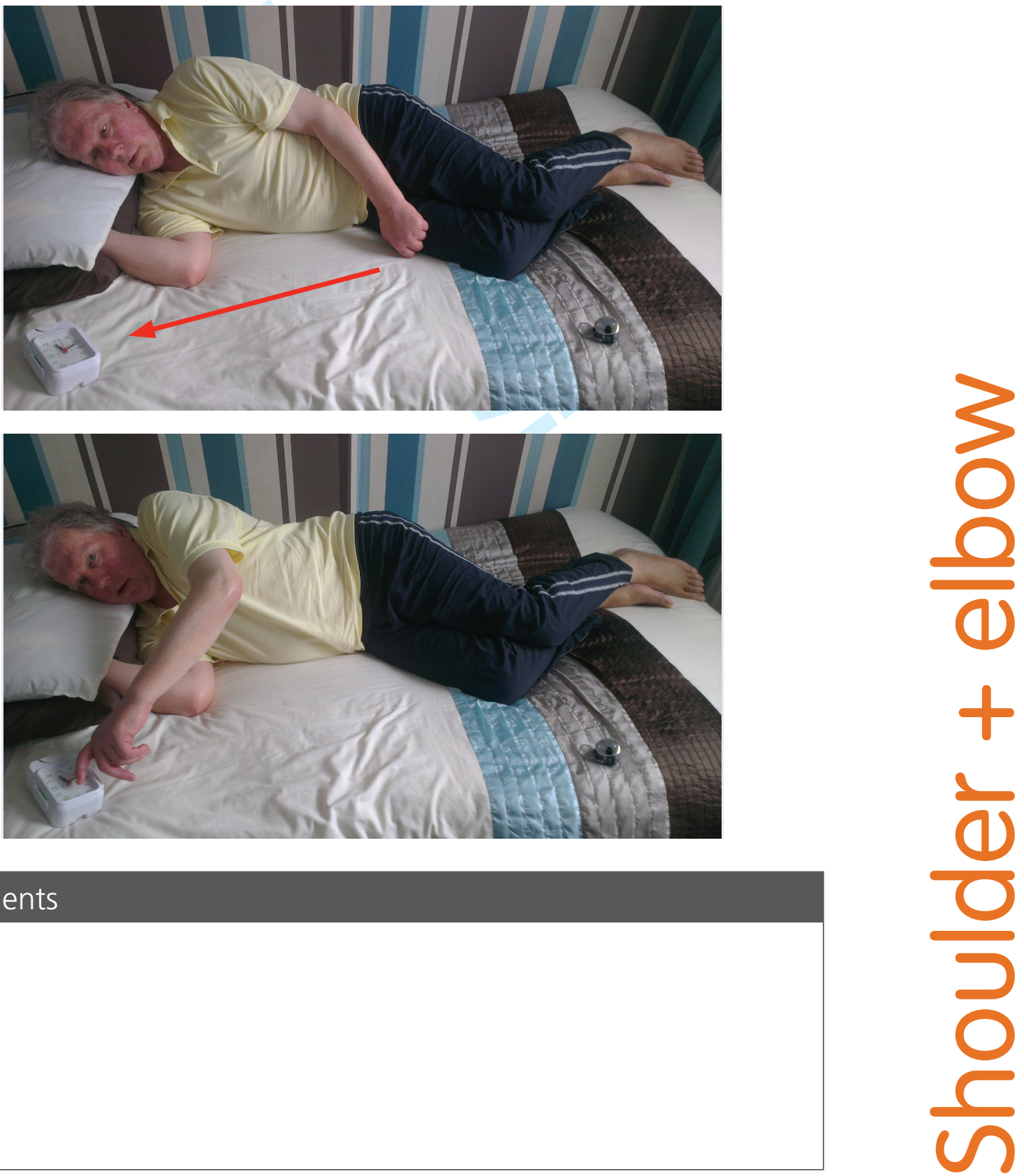


\section{8}

\section{Sliding object forward to touch}

- $\quad$ Sit with your forearm supported on a flat surface and an object in your hand

- Position an object in front of you as a target.

- $\quad$ Slide your hand forwards to touch the target

- Try to stay facing forwards and keep your back in contact with the chair.
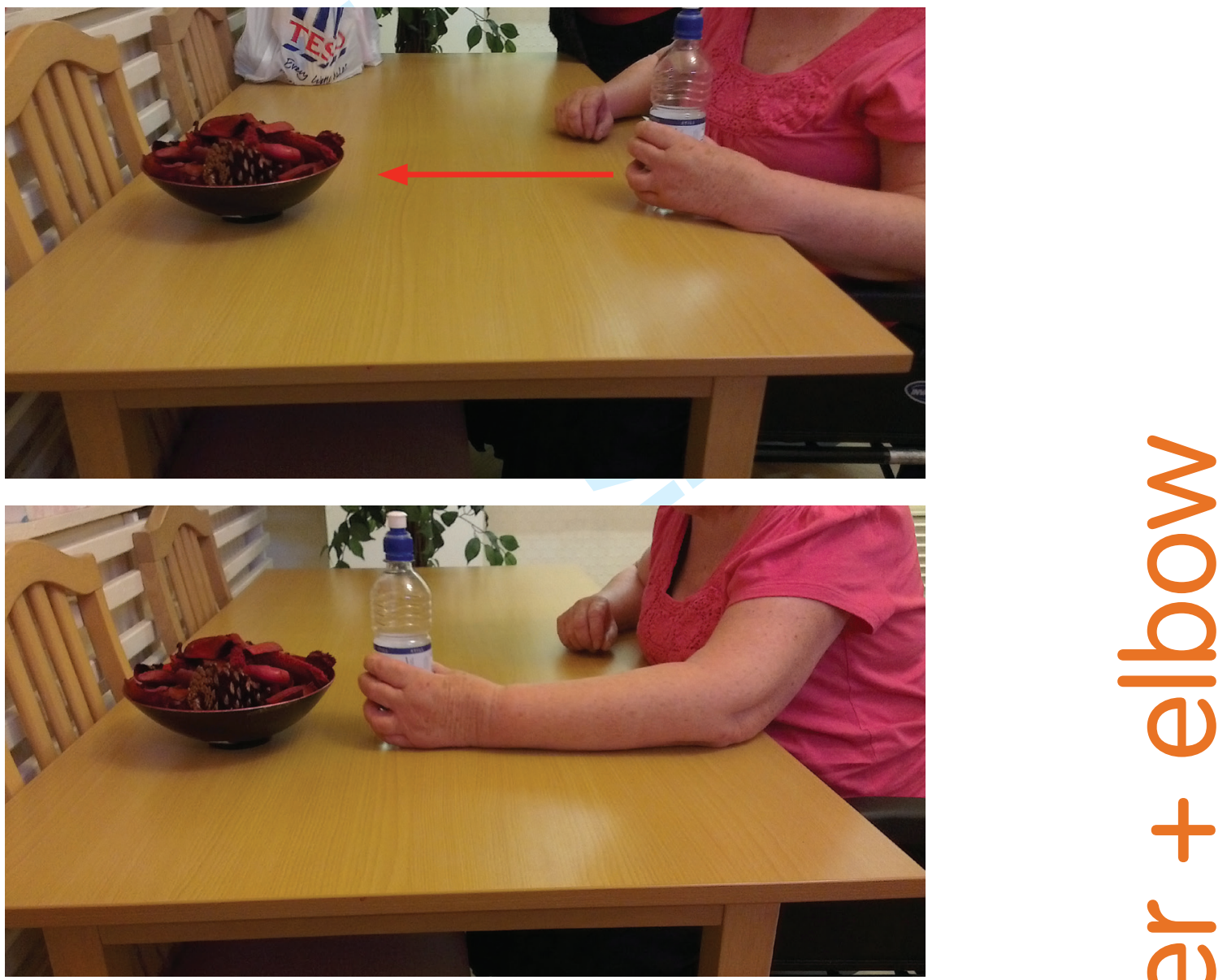

1

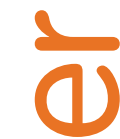

Comments 
Move object between

and

\section{and} and

- $\quad$ Sit with an object in your hand

- Lift the object and move to different targets on the flat surface in front of you

- Your therapist can provide you with a large piece of paper with 'markers' on it.
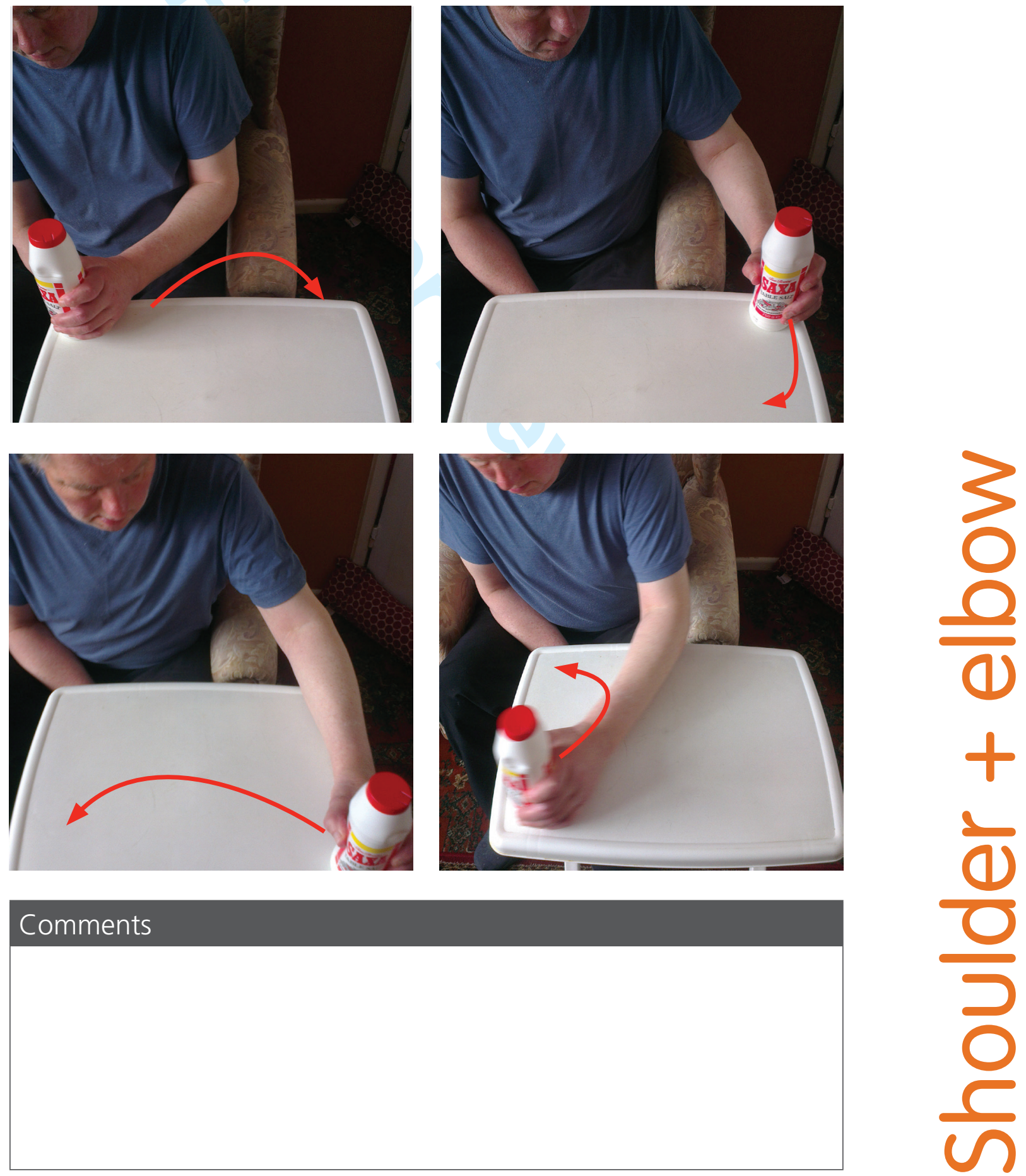


\section{Lift cup onto coaster}

- Sit at a flat surface with a cup in your hand

- Position a coaster next to your wrist

- Lift the cup and bend your wrist backwards to place the cup onto the coaster

- Try to keep your forearm still so only your hand is moving
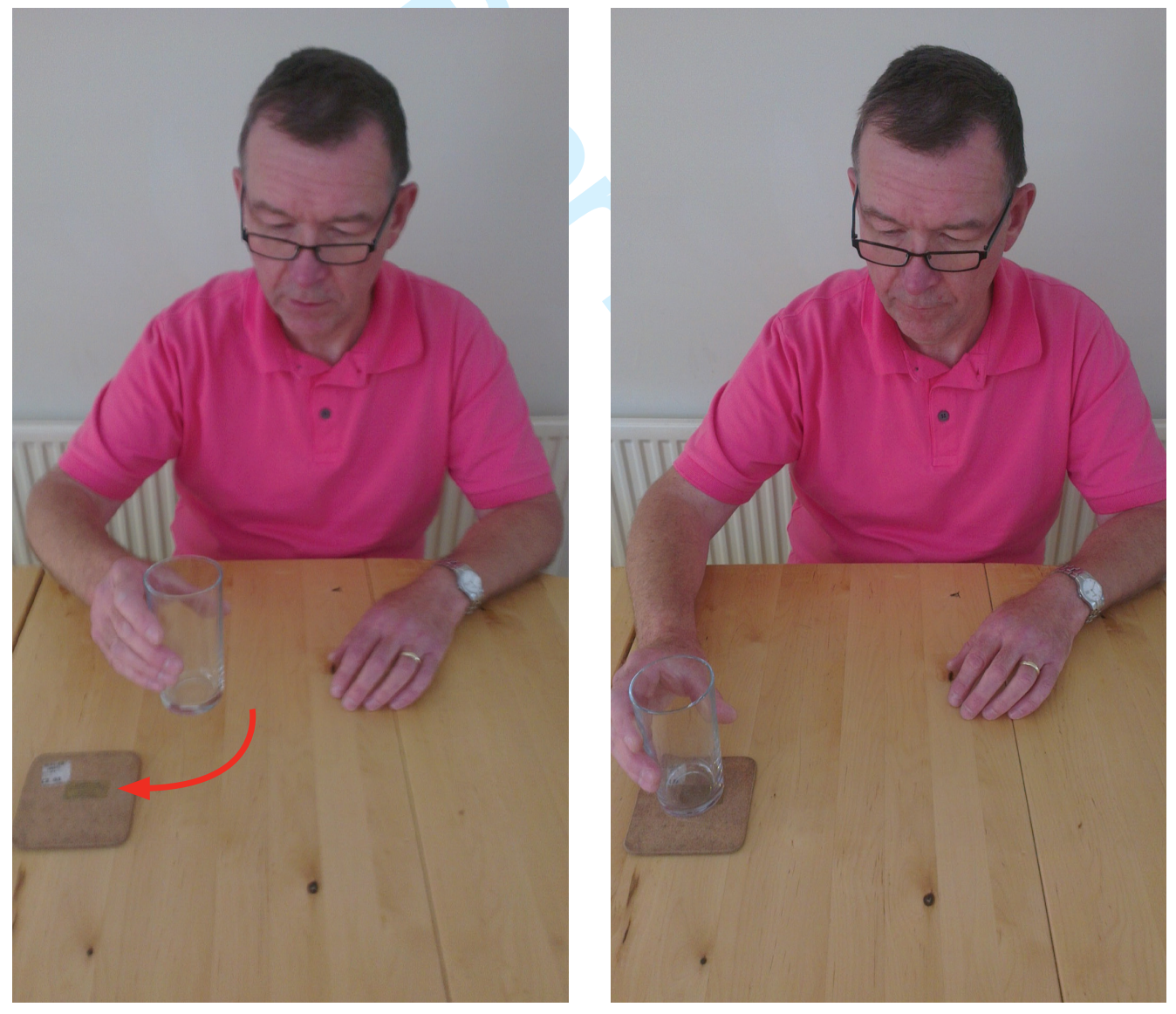

\section{Comments}




\section{Peg out washing}

- Using two hands, practise pegging items of clothing onto a washing line.

- Try also practising taking the items of clothes down without them dropping on the floor.
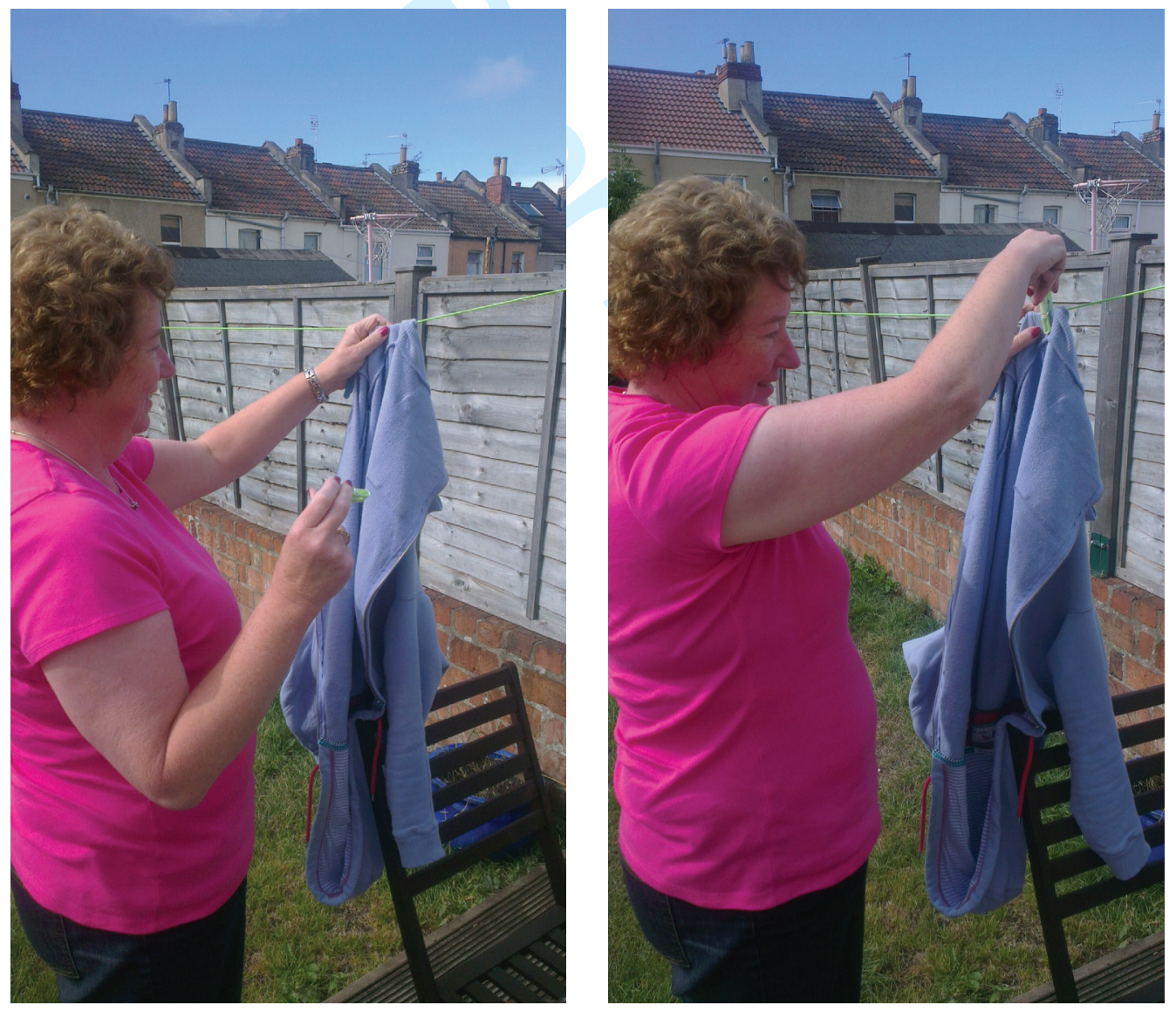

Comments 


\section{PARTICIPANT QUESTIONNAIRE}

\section{Evaluation of home-based reach to grasp training after stroke.}

Participant number

Date of interview

The research team would like to find out what you thought about the Reach to Grasp training you've received. I have a few questions to ask you about it. Please try to tell me what you really think; you will not upset me if you tell me you didn't like anything.

1. a) Do you think the number of visits during the six weeks was an acceptable or unacceptable amount?
Acceptable
Unacceptable

b) If unacceptable, how would you alter the visits?

2. a) Do you think being asked to practice by yourself for an hour a day was an acceptable or unacceptable amount of time?

\section{Acceptable}

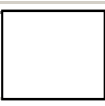

Unacceptable

b) If unacceptable, how long do you think would be an acceptable amount of time for you?

3. a) Did you find the reach to grasp training an acceptable or unacceptable physiotherapy treatment?

\begin{tabular}{|l|l|l|}
\hline Acceptable & Unacceptable $\square$ \\
\hline
\end{tabular}

b) Why?

4. How beneficial do you think the treatment was for you?

\begin{tabular}{|c|c|c|c|c|c|c|c|c|c|c|}
\hline 0 & 1 & 2 & 3 & 4 & 5 & 6 & 7 & 8 & 9 & 10 \\
\hline
\end{tabular}

(6) $0=$ not beneficial at all, $10=$ extremely beneficial

(ن)

5. What difference do you think the treatment has made to you?

6. Has the treatment made a difference to your ability to use the arm?

Yes $\square$ No $\square$


7. If yes, what can you do now that you couldn't do when you joined the trial?

8. Was the amount of improvement in your arm or hand movement over the last six weeks worth the work you did?

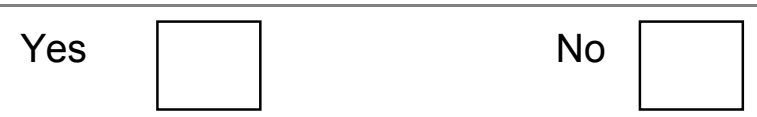

9. How difficult did you find the treatment?

\begin{tabular}{|c|c|c|c|c|c|c|c|c|c|c|}
\hline 0 & 1 & 2 & 3 & 4 & 5 & 6 & 7 & 8 & 9 & 10 \\
\hline
\end{tabular}

(ூ)

$0=$ extremely difficult, 10 = extremely easy

(ن)

10. I'm going to show you all the exercise sheets you used. Please tell me which ones you liked and which you didn't like. [Therapist to list exercise number and put a tick or a cross next to each]

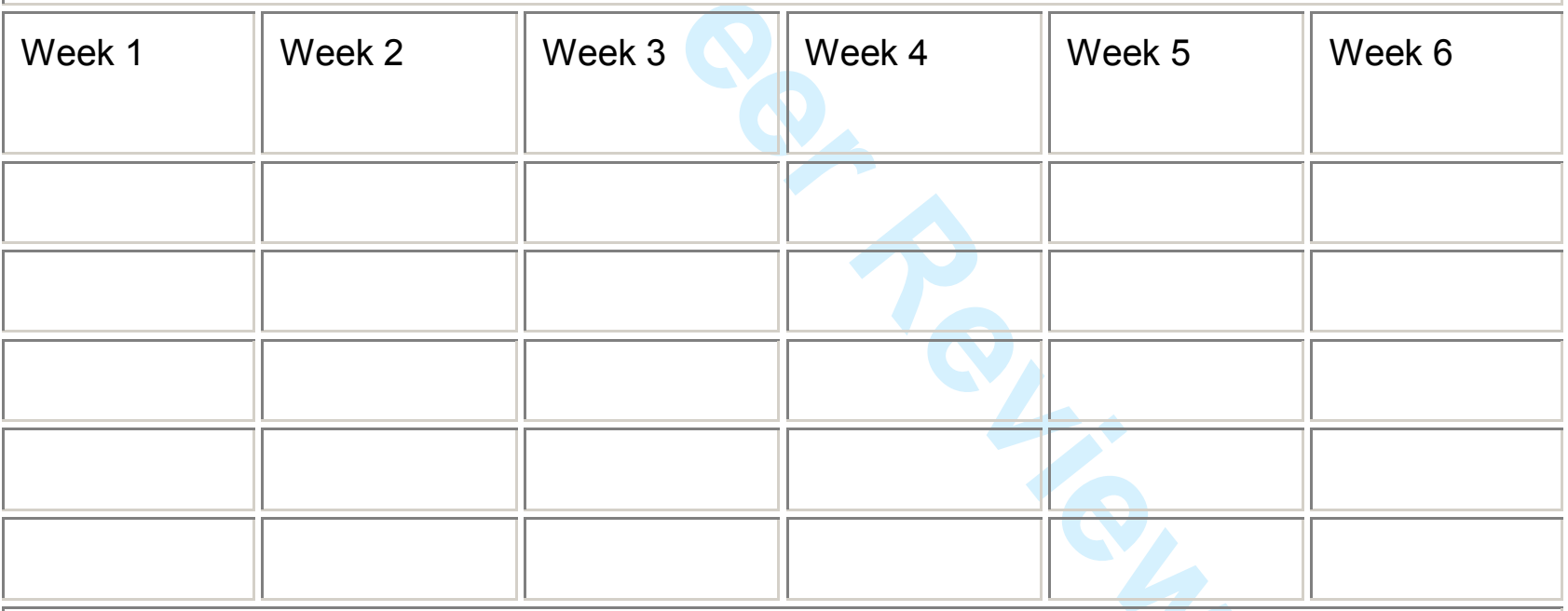

11. a) What aspects of the design of the activity sheets did you like?

b) Are there any changes to the design of the exercise sheets you would like to see?

12. Do you have any other comments about the reach to grasp training or your experience of it? 


\section{Intervention Questionnaire: qualitative responses to questions 5 and 7 on reported benefits of reach-to-grasp training.}

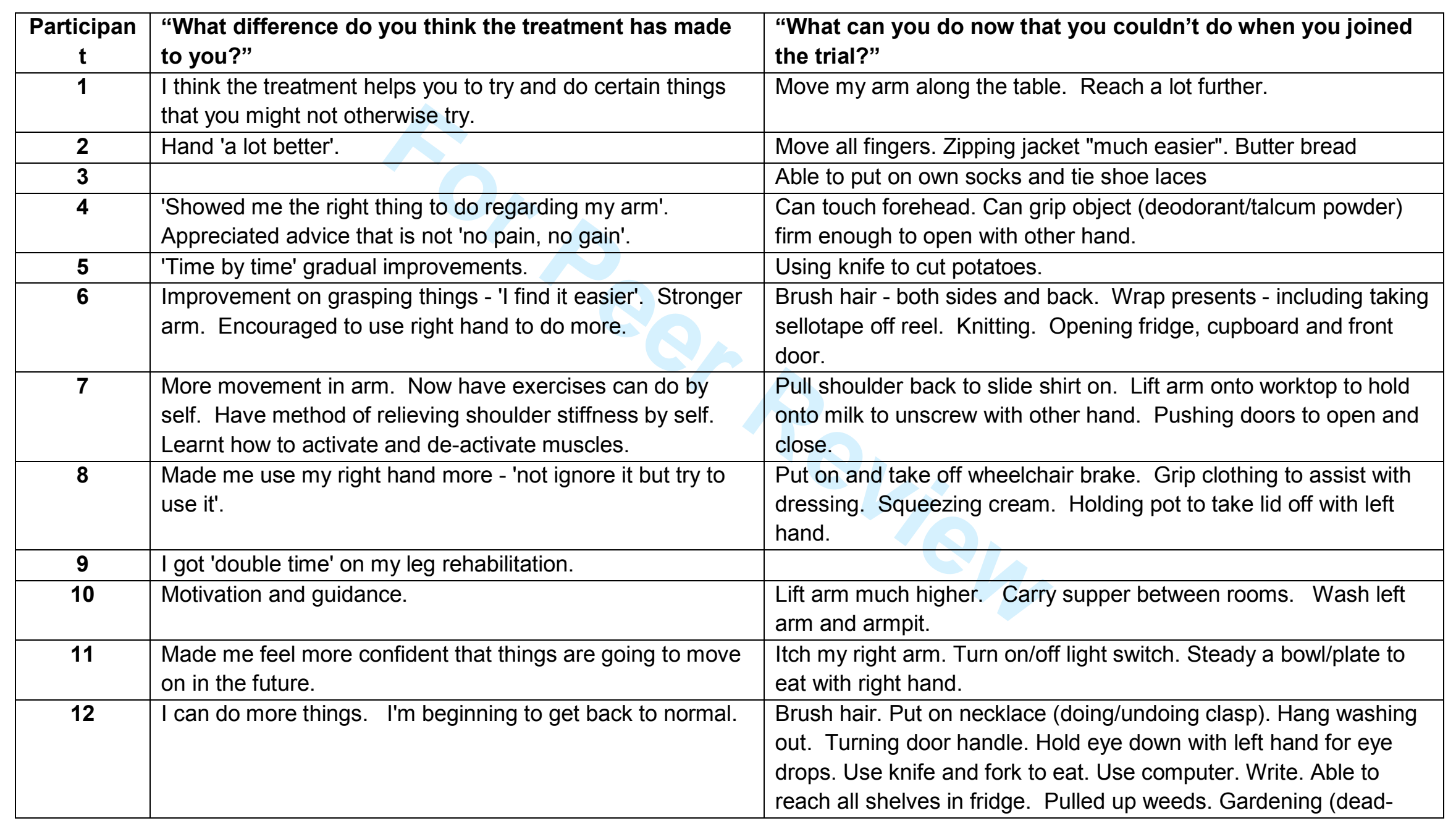

Revised RtG Intervention paper online data supplement - 'Intervention Questionnaire' 


\begin{tabular}{|c|c|c|}
\hline & & $\begin{array}{l}\text { heading flowers). Knitting. Open drawers and sort cutlery. } \\
\text { Brushing/mopping floor. Walk up and down stairs using the left } \\
\text { hand rail only. Ironing. }\end{array}$ \\
\hline 13 & $\begin{array}{l}\text { I've been able to see what is needed to help improve my } \\
\text { arm. Using arm more automatically. Given confidence. }\end{array}$ & $\begin{array}{l}\text { Use left arm to help get from lying to sitting. Brushing hair. Drink } \\
\text { from a beaker. Using left hand on Zimmer Frame. Picking up and } \\
\text { moving objects. Grasp tighter and not drop things as much. }\end{array}$ \\
\hline 14 & More movement. More confidence to try things in my life. & $\begin{array}{l}\text { Open and close hand and Lift arm. - Turn bathroom tap and light } \\
\text { cord on and off. }\end{array}$ \\
\hline 17 & $\begin{array}{l}\text { Able to reach for Zimmer frame by myself, meaning I can } \\
\text { walk by myself. }\end{array}$ & $\begin{array}{l}\text { Able to reach for Zimmer frame by myself, meaning I can walk by } \\
\text { myself. }\end{array}$ \\
\hline 18 & $\begin{array}{l}\text { Can move arm more but not particularly functional still. Did } \\
\text { not meet objective of being able to put weight through arm. }\end{array}$ & \\
\hline 19 & Not much difference although I do things better. & I can reach up higher. \\
\hline 20 & $\begin{array}{l}\text { Would now try other things more frequently. Taking more } \\
\text { notice of arm. }\end{array}$ & 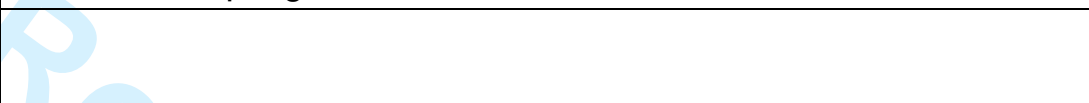 \\
\hline 22 & $\begin{array}{l}\text { Husband answered due to participant's aphasia - Hasn't } \\
\text { seen a lot of difference in movement but 'early days'. } \\
\text { Psychologically 'appreciated' what's happened. }\end{array}$ & \\
\hline 23 & Encouraged me to try everything. & $\begin{array}{l}\text { Knitting. Writing. Pouring. Picking heavier objects up and reaching } \\
\text { out to side. Peeling orange. }\end{array}$ \\
\hline 24 & Gave me more movement. Made me feel better. & $\begin{array}{l}\text { Walk further and feel better about it as arm doesn't ache. Do } \\
\text { exercises. Get dressed better, e.g. able to put top over head by } \\
\text { self now. }\end{array}$ \\
\hline
\end{tabular}

Revised RtG Intervention paper online data supplement - 'Intervention Questionnaire' 


\title{
Task-specific reach-to-grasp training after stroke:
}

\section{development and description of a home-based intervention}

\section{[Clinical Rehabilitation - 'Rehabilitation in Practice']}

\author{
Abstract: 236 words \\ Objective: \\ To describe and justify the development of a home-based, task-specific upper limb training \\ intervention to improve reach-to-grasp after stroke and pilot it for feasibility and \\ acceptability prior to a randomised controlled trial. \\ Intervention description:
}

The intervention is based on intensive practice of whole reach-to-grasp tasks and partpractice of essential reach-to-grasp components. A 'pilot' manual of activities covering the domains of self-care, leisure and productivity was developed for the feasibility study. The intervention comprises 14 hours of therapist-delivered sessions over 6 weeks, with additional self-practice recommended for 42 hours (i.e. 1 hour every day). As part of a feasibility randomised controlled trial, 24 people with a wide range of upper limb impairment after stroke experienced the intervention to test adherence and acceptability. The median number of repetitions in 1-hour therapist-delivered sessions was 157 (IQR: 96211). The amount of self-practice was poorly documented. Where recorded, median 
amount of practice was 30 minutes (IQR: 22-45) per day. Findings demonstrated that the majority of participants found the intensity, content and level of difficulty of the intervention acceptable, and the programme to be beneficial. Comments on the content and presentation of the self-practice material were incorporated in a revised 'final' intervention manual.

\section{Discussion:}

A comprehensive training intervention to improve reach-to-grasp for people living at home after stroke has been described in accordance with the TIDieR reporting guidelines. The intervention has been piloted, found to be acceptable and feasible in the home setting.

\section{Keywords:}

Stroke, Hand, Arm, Upper Limb, Physical therapy, Occupational therapy, Rehabilitation, Home, Reach, Grasp, Repetitive, Task-specific training, Practice

Trial registration: ISRCTN56716589 